\title{
Open Versus Laparoscopic Pyloromyotomy for Hypertrophic Pyloric Stenosis: A Systematic Review and Meta-Analysis Focusing on Major Complications
}

\author{
M. W. N. Oomen $\cdot$ L. T. Hoekstra . \\ R. Bakx • D. T. Ubbink • H. A. Heij
}

Received: 19 September 2011/ Accepted: 13 January 2012/Published online: 21 February 2012

(C) The Author(s) 2012. This article is published with open access at Springerlink.com

\begin{abstract}
Background There is an ongoing debate about whether laparoscopic pyloromyotomy (LP) or open pyloromyotomy (OP) is the best option for treating hypertrophic pyloric stenosis (HPS). The aim of this study was to compare the results of both surgical strategies by means of a systematic review and meta-analysis of the available literature.

Methods A systematic search for randomized clinical trials (RCTs) comparing OP and LP was conducted. Studies were reviewed independently for quality, inclusion and exclusion criteria, and outcomes. Primary outcome was major postoperative complications (i.e., incomplete pyloromyotomy, perforation, and need for reoperation). Secondary outcomes were time to full feed, postoperative hospital stay, and any other postoperative complications.

Results Four RCTs with a total of 502 patients (OP 255, LP 247) fulfilled the inclusion criteria and were analyzed in this review. These trials showed an absolute incidence of major postoperative complications of $4.9 \%$ in the LP group. Metaanalysis showed that LP did not lead to significantly more major postoperative complications (ARR 3\%, 95\% CI -3 to
\end{abstract}

\footnotetext{
M. W. N. Oomen $(\varangle) \cdot$ R. Bakx $\cdot$ H. A. Heij

Department of Pediatric Surgery, Academic Medical Center, Meibergdreef 9, 1105, AZ, Amsterdam, The Netherlands

e-mail: m.w.oomen@amc.uva.nl

L. T. Hoekstra

Department of Surgery (Surgical Laboratory), Academic Medical Center, Meibergdreef 9, 1105, AZ, Amsterdam,

The Netherlands

D. T. Ubbink

Departments of Quality Assurance and Process Innovation and Surgery, Academic Medical Center, Amsterdam, The Netherlands
}

$8 \%)$ than OP. The mean difference in time to full feed was significant $(2.27 \mathrm{~h}, 95 \% \mathrm{CI}-4.26$ to $-0.29 \mathrm{~h})$ and the mean difference in postoperative hospital stay tended to be shorter (2.41 h, 95\% CI -6.10 to $1.28 \mathrm{~h}$ ), both in favor of LP.

Conclusion So far, the major postoperative complication rate after LP for HPS is not substantially higher than after OP. Because time to full feed and postoperative hospital stay are at best a few hours shorter after LP than after OP, the laparoscopic technique might be acknowledged as the standard of care if the major postoperative complication rate is low. Hence, this laparoscopic procedure should preferably be performed in centers with pediatric surgeons with expertise in this procedure.

\section{Keywords Abdominal - Pediatric · Endoscopy ·} Complications $\cdot$ Pyloric $\cdot$ Review

Hypertrophic pyloric stenosis (HPS) is a common problem that is often seen in daily care in the pediatric surgical unit. The incidence of HPS is approximately 1-3 per 1,000 live births [1]. HPS is seen more often in males, with a male-tofemale ratio of 4:1 [2]. The surgical treatment of choice in the last century has been the longitudinal splitting of the seromuscular layer of the pylorus without suturing, which is defined as "pyloromyotomy." The constriction is relieved and allows normal passage of stomach contents into the duodenum. The operation traditionally has been performed through a classical right-upper-quadrant (RUQ) transverse incision. This operation is effective at providing excellent exposure of the pylorus but results in an abdominal scar that grows with the patient and becomes quite significant with time.

Several other approaches have been introduced, such as that described by Tan and Bianchi [3] in which the 
pyloromyotomy is performed through a supraumbilical skin fold incision. This technique achieves an excellent cosmetic outcome with an apparently unscarred abdomen. Alain et al. [4] introduced the laparoscopic approach in 1991. Both surgical modalities have gained wide acceptance in the western world. The potential advantages of the laparoscopic pyloromyotomy (LP) are shorter hospital stay, improved cosmesis, shorter postoperative recovery, lower complication rates, and less postoperative pain [4-13]. These studies had different primary outcomes and subsequently reported advantages in favor of LP. None had complications as a primary outcome.

However, recently a review was published in which a difference in time to full feed of $12 \mathrm{~h}$ ( $3 \mathrm{~h}$ if only randomized clinical trials [RCTs] were encountered) and an earlier hospital discharge of $6 \mathrm{~h}$ ( $4 \mathrm{~h}$ if only RCTs were included) was found [12]. Both do not seem to offer convincing clinical relevance to promote LP apart from the cosmetic advantage. This review included complications, but the reduced complication rates in the LP group were due to mainly wound complications. In our opinion, a valid argument in favor of LP could be a reduction in major postoperative complications. The question arises if LP is a better operation technique for HPS in terms of postoperative complications and is therefore superior to the open approach.

Therefore, the aim of this study was to compare the results of LP and open pyloromyotomy (OP) by means of a systematic review of the available randomized trials while focusing on major complications (i.e., incomplete pyloromyotomy, perforation, and need for re-operation).

\section{Materials and Methods}

\section{Search Strategy}

A systematic search for RCTs that compared open and LP was conducted. Retrieval of studies was performed through a systematic search of the databases PubMed, Ovid (Ovid Technologies, New York, NY) and Cochrane (Cochrane database of systematic reviews). Keywords and medical subject heading (MeSH) terms used were "pyloric stenosis," "pyloromyotomy," "comparative studies," "open," "laparoscopic," and "postoperative complications." The full texts of the studies were read to determine whether the studies met the inclusion criteria. The reference lists of all articles that dealt with the topic of interest were scanned to check for additional publications. Disagreements about the inclusion of studies were resolved by group discussion (MWNO, RB, LTH). There were no language restrictions. No unpublished data were encountered.
Study Selection

Potentially eligible studies were reviewed independently by two authors (MWNO, RB) for inclusion and exclusion criteria. Studies were included in the review if they were RCTs that compared the results of LP and OP in children with HPS with admission time after pyloromyotomy and postoperative complication rate as outcomes. The primary outcome was major postoperative complications (i.e., incomplete pyloromyotomy, perforation, and need for reoperation). Secondary outcomes were time to full feed, postoperative hospital stay, and any other postoperative complications.

\section{Data Collection}

From the included studies, data on setting, methodological quality [according to the Cochrane handbook for systematic reviews of interventions (http://dcc.cochrane.org/sites/ dcc.cochrane.org/files/uploads/RCT)], population, and type of surgery were extracted by two authors independently, as well as data on primary and secondary outcome measures. The reporting checklist proposed by the Consolidated Standards of Reporting Trials (CONSORT) group [14, 15] was used as a guideline when performing this review.

\section{Statistical Methods}

Review Manager (RevMan) software ver. 5.0 (The Nordic Cochrane Center, The Cochrane Collaboration, Copenhagen, 2008) was used for data entry and statistical analysis. Continuous data are expressed as mean differences, with standard deviations (SD) or medians and interquartile ranges (IQR) where appropriate. Results for comparisons of dichotomous outcomes (e.g., major postoperative complications) are expressed as risk differences [or absolute risk reduction, ARR) with $95 \%$ confidence intervals (CI)]. A meta-analysis was planned if the included studies were clinically homogeneous. Statistical heterogeneity in the meta-analysis was assessed with the $\chi^{2}$ test and the $I^{2}$ index. If $I^{2}$ was above $30 \%$, a random-effects approach instead of a fixed-effect analysis would be undertaken. If $I^{2}$ was over $60 \%$, we would refrain from meta-analysis.

\section{Results}

The initial search yielded 361 potentially relevant articles, of which 346 articles were excluded because of failure to meet the inclusion criteria (Fig. 1). Fifteen full papers were retrieved for more information of which 11 
Fig. 1 Number of articles identified and screened in the systematic review

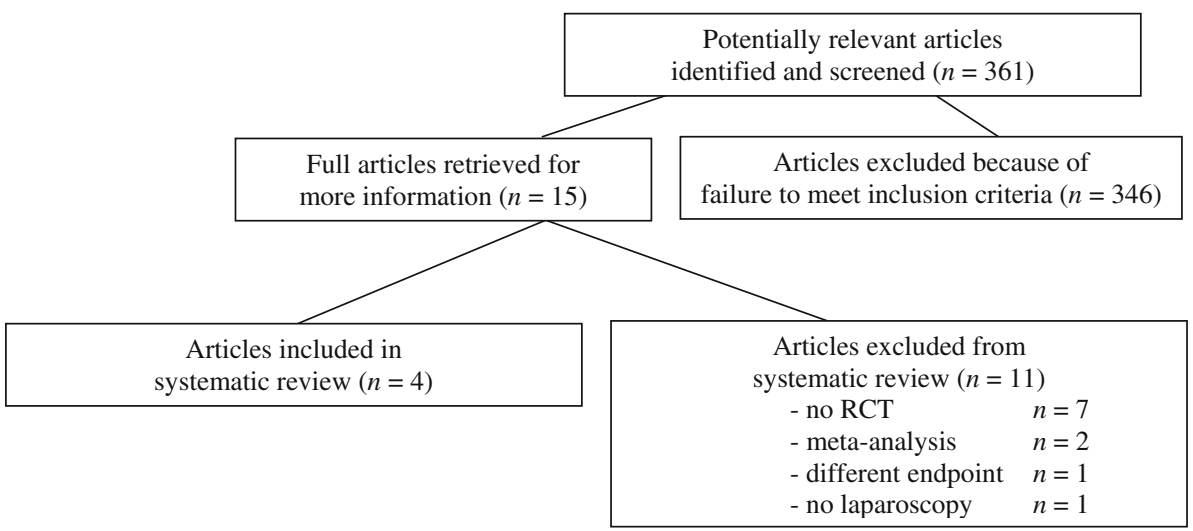

Table 1 Study details of all RCTs

\begin{tabular}{|c|c|c|c|}
\hline Reference & $n(\mathrm{OP}, \mathrm{LP})$ & Center type $(n)$ & Surgical technique \\
\hline Hall et al. [7] & $180(93,87)$ & Multicenter (6) & $\begin{array}{l}\text { OP: Tan and Bianchi [3] } \\
\text { LP: Najmaldin and Tan [22] }\end{array}$ \\
\hline Leclair et al. [8] & $102(52,50)$ & Single center & $\begin{array}{l}\text { OP: Longitudinal seromuscular incision } \\
\text { LP: Umbilical incision, avascular plane }\end{array}$ \\
\hline St. Peter et al. [13] & $200(100,100)$ & Single center & $\begin{array}{l}\text { OP: According to surgeon's personal technique } \\
\text { LP: Umbilical stab incision technique }\end{array}$ \\
\hline Greason et al. [6] & $20(10,10)$ & Single center & $\begin{array}{l}\text { OP: Umbilical fold incision } \\
\text { LP: Modified version of Najmaldin and Tan [22] } \\
\text { Superior umbilical fold region }\end{array}$ \\
\hline
\end{tabular}

Table 2 Quality check of all RCTs

\begin{tabular}{lllll}
\hline Reference & Randomization & Blinded & Allocation concealment & Follow-up (range) \\
\hline Hall et al. [7] & Randomly assigned & Double-blind & $\begin{array}{c}\text { Facsimile communication with leading } \\
\text { center or online via website }\end{array}$ & $\begin{array}{c}\text { 39 days }{ }^{\mathrm{a}}(32-51,12-179) \\
(n=151)\end{array}$ \\
$\begin{array}{l}\text { Leclair et al. [8] } \\
\text { St. Peter et al. [13] }\end{array}$ & $\begin{array}{l}\text { Sealed numbered envelopes } \\
\text { Non-stratified sequence } \\
\text { in blocks of ten }\end{array}$ & $\begin{array}{l}\text { Double-blind } \\
\text { No blinding }\end{array}$ & Operation discussed with family & weeks $(n=102)$ \\
Greason et al. [6] & Sealed numbered envelopes & & & \\
\hline
\end{tabular}

${ }^{a}$ Median results after discharge allocation criteria according to the Cochrane handbook for systematic reviews of interventions

b Patients were randomized; the surgical procedure was blinded to parents and caregivers; patient characteristics were comparable; $84 \%$ of the patients attended a follow-up appointment; analysis was performed according to the assigned group; patients were treated equally in both groups

c An individual unit of randomization in a non-stratified sequence was used; the operation was blinded to patients; health-care professionals were aware of the treatment assigned; there were no differences between the groups at the beginning of the study; the follow-up was complete in both groups; all patients were analyzed according to the group in which they were allocated; there were no differences in treatment, besides the procedure

studies were excluded from the systematic review. These excluded articles were not randomized controlled trials [5, 11, 16-18], consisted only of a meta-analysis [19], used different end points [20] or different treatment strategies [21] and a RCT in which no laparoscopy was performed. Four RCTs with a total of 502 patients (OP 255, LP 247) fulfilled the inclusion criteria and were analyzed in this review [6-8, 13]. Study details and the quality check of all RCTs are given in Tables 1, 2, respectively. 


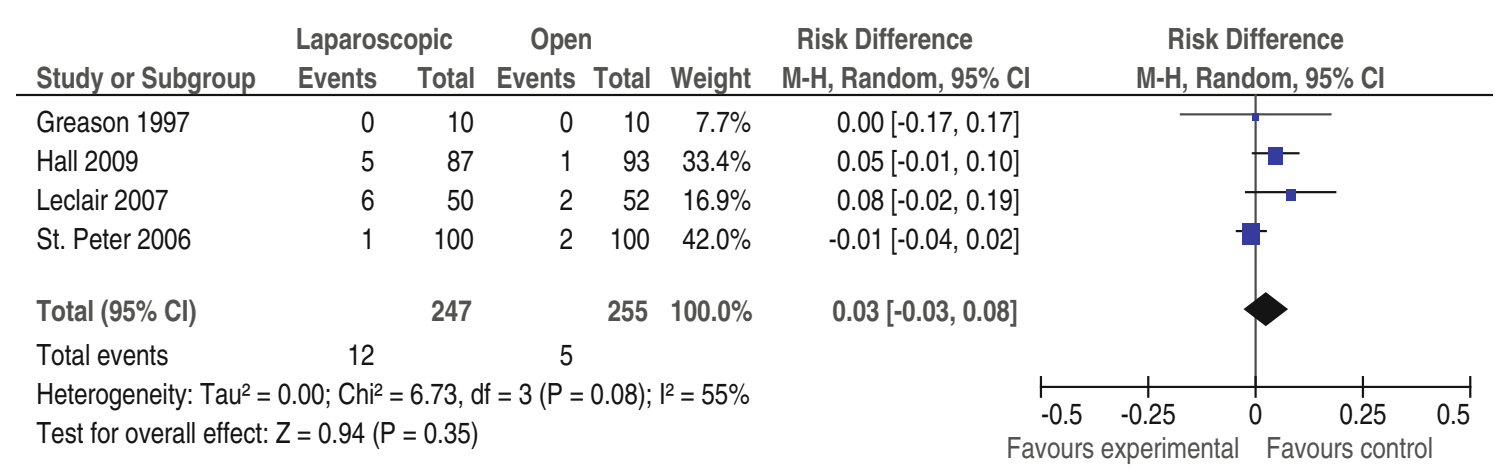

Fig. 2 Forest plot of major postoperative complications in infants treated with OP and LP

Postoperative Complications

\section{Major Postoperative Complications}

All studies included in this review reported major complications, with a total of $12(4.9 \%)$ major complications in children who underwent LP and $5(2.0 \%)$ in the OP group $[6-8,13]$. Using a random-effects approach, we found no significant difference between LP and OP (ARR 3\%, 95\% $\mathrm{CI}-3-8 \%$ ). The forest plot comparing major postoperative complications is shown in Fig. 2.

\section{All Postoperative Complications}

All four studies described postoperative complications, with only one complication in the OP group in the study by Greason et al. [6], which did not require treatment [6-8, 13]. In summary, a nonsignificant difference was found of $26(10.5 \%)$ complications in the LP group versus 28 $(11.0 \%)$ complications in the OP group. A forest plot is shown in Fig. 3.

Time to Full Feed

Three RCTs reported on the results of the mean time after surgery to return to full feedings $[6,8,13]$. Two studies
$[8,13]$ showed no difference in time to full feed between LP and OP and one study [6] did report a difference. The mean time to full feeding in this article was less in the LP group ( $4.4 \mathrm{~h}$ ) than in the OP group $(8.9 \mathrm{~h})$. The data of Hall et al. [7] were medians and thus not suitable for the random-effects model. In conclusion, the mean difference in time to full feed was $2.27 \mathrm{~h}$ in our review, in favor of LP (Fig. 4). This difference was statistically significant (95\% CI $0.29-4.26 \mathrm{~h}$ ).

\section{Postoperative Hospital Stay}

There were no differences in length of postoperative stay between both treatment groups mentioned by the studies separately [6, 8, 13]. Hall et al. [7] again showed median values and was therefore excluded. In our meta-analysis we also found no significant difference in postoperative hospital stay (mean difference $=2.41 \mathrm{~h}, 95 \%$ CI $-6.10-1.28 \mathrm{~h}$ ) (Fig. 5).

\section{Discussion}

There are still contradictory results in the literature with regard to the benefits and disadvantages of LP compared to the open procedure to treat infants with HPS. In our

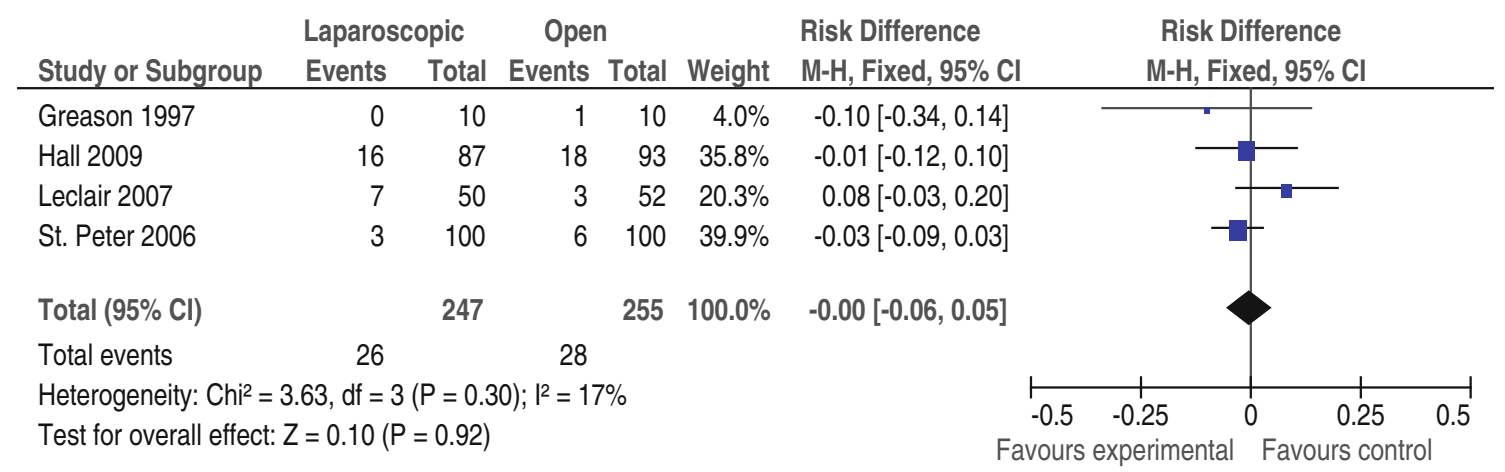

Fig. 3 Forest plot of all postoperative complications 


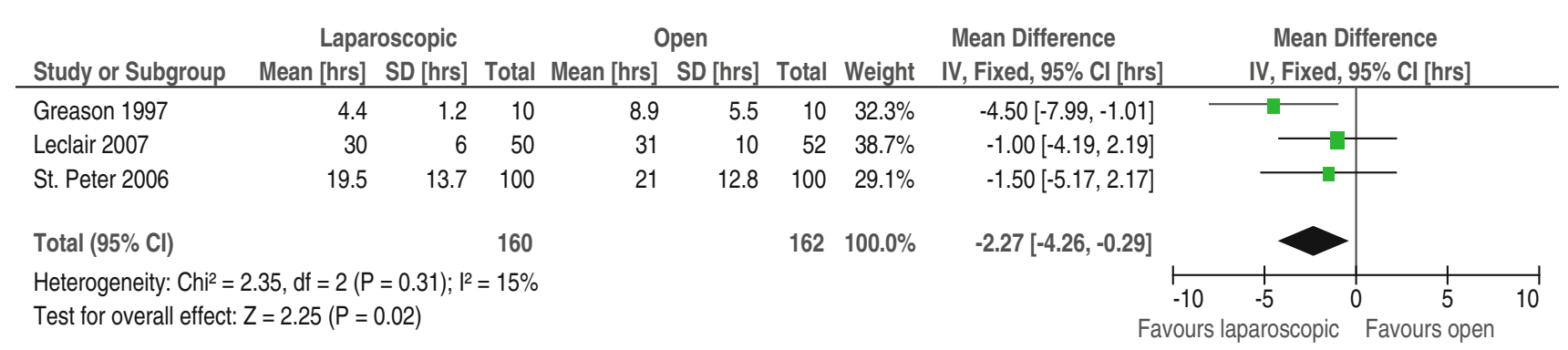

Fig. 4 Forest plot of time to full feed in hours

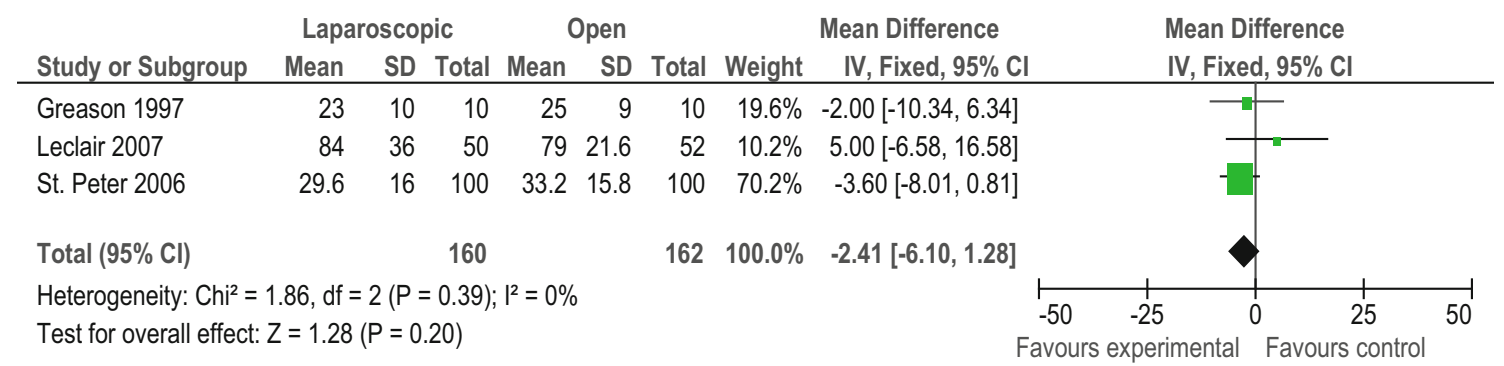

Fig. 5 Forest plot of length of postoperative stay in hours

systematic review of high-level evidence, LP was found to be superior to OP with respect to a shorter time to full feed but not regarding (major) postoperative complications or length of hospital stay. Despite this small benefit, LP can be acknowledged as the standard of care only if the major postoperative complication rate is substantially reduced.

In this area of rapidly evolving technology, minimally invasive procedures are still a topic of interest in medicine. In pediatric surgery the number of minimally invasive procedures performed is still rising as more institutes in several countries are encouraged to do so. However, in the world of adult minimally invasive surgery, quite a few complications have occurred leading to criticism in the national health-care inspectorate [23]. More thorough research is therefore necessary to find out whether minimally invasive procedures are merely another technological improvement or a real clinical step forward. In pediatric surgery, surgical changes in the treatment of hypertrophic pyloromyotomy are a change from the classical RUQ incision toward the supraumbilical approach and, since 1991, the laparoscopic procedure as introduced by Alain et al. [4].

Recently, a systematic review and meta-analysis was published by Sola et al. [12] who compared complication rates and outcomes of laparoscopic and OP in infants with HPS. However, in our opinion, there are some shortcomings in their results. First, six prospective studies $[5-8,11$, 13] were included, of which four were RCTs $[6-8,13]$. Although, the studies by Fujimoto et al. [5] and Scorpio et al. [11] were prospective studies, they were not randomized and are therefore at higher risk of bias. However, these studies did not alter the results of the comparison of total complications in the OP and LP groups. Second, the study by Hall et al. [7] was included, although it used median results, and the other study [12] used mean values. This is a source of bias that weakens the results. Besides, one study reported was a prospective cohort study [11], which is statistically not comparable with RCTs in a systematic review. Again, there is a risk of potential bias. Furthermore, to our knowledge there is no randomized clinical trial or systematic review that described (major) complications as a primary outcome, which should be appreciated together with the possible positive outcomes.

It is important to note that every hospital has different standardized protocols for a feeding regimen, which makes an objective comparison difficult. A postoperative feeding schedule was started $6 \mathrm{~h}$ after recovery from anesthesia in the study of Hall et al. [7], while in the study of Leclair et al. [8], the feeding regimen was initiated $18 \mathrm{~h}$ after the operation. St. Peter et al. [13] maintained a feeding schedule in which feedings were started $2 \mathrm{~h}$ postoperatively. A breast-fed infant started ad libitum feeding $6 \mathrm{~h}$ after the pyloromyotomy in the study by Greason et al. [6]

The four studies selected for our review are RCTs, but they differ in the number of patients treated (Hall [7], 180; Leclair [8], 102; St. Peter [13], 200; and Greason [6], 20). In any procedure that is introduced into daily surgical care, new problems can occur during and after surgery that were not recognized or foreseen by the surgeon and his team. This learning curve in the four RCTs plays an 
underestimated role in major complications seen in the laparoscopic group, which may also have influenced secondary outcomes such as postoperative hospital stay. In our opinion RCT that compares two procedures, the surgeon(s) should be beyond the learning curve(s) of both operations in order to make a valid comparison. More learning curves should be defined for minimally invasive procedures [24] to make better studies possible to answer whether minimally invasive surgery is an alternative to open surgery or is the gold standard. This is not only mandatory for clinical reasons, but also when training new surgeons in these technically demanding procedures.

We know that for adult patients minimally invasive surgery has some benefits over open surgery by means of better cosmesis, body image, and postoperative complications [25-27]. Cosmesis and body image may be important to the parents of children with HPS, and later in life they may be important to our pediatric patients themselves.

In this systematic review we summarized all RCTs available in the pediatric surgical literature, focusing mainly on major complications that need surgical reintervention in patients with HPS. However, our results show no clear benefit of the laparoscopic procedure over the open operation. Time to full feed was found to be significantly shorter in the laparoscopic group, but this is measured in hours and therefore seems barely clinically significant. If the surgeon is able to perform both procedures, it is at the discretion of the surgeon or center to make a well-founded decision between the two options.

Acknowledgments Disclosures Dr. M. W. N. Oomen, Dr. L. T. Hoekstra, Dr. R. Bakx, Dr. D. T. Ubbink, and Prof. Dr. H. A. Heij have no conflicts of interest or financial ties to disclose.

Open Access This article is distributed under the terms of the Creative Commons Attribution License which permits any use, distribution, and reproduction in any medium, provided the original author(s) and the source are credited.

\section{References}

1. Grant GA, McAleer JJ (1984) Incidence of infantile hypertrophic pyloric stenosis. Lancet 1:1177

2. Everett KV, Capon F, Georgoula C, Chioza BA, Reece A, Jaswon M, Pierro A, Puri P, Gardiner RM, Chung EM (2008) Linkage of monogenic infantile hypertrophic pyloric stenosis to chromosome 16q24. Eur J Hum Genet 16:1151-1154

3. Tan KC, Bianchi A (1986) Circumumbilical incision for pyloromyotomy. Br J Surg 73:399

4. Alain JL, Grousseau D, Terrier G (1991) Extramucosal pyloromyotomy by laparoscopy. Surg Endosc 5:174-175

5. Fujimoto T, Lane GJ, Segawa O, Esaki S, Miyano T (1999) Laparoscopic extramucosal pyloromyotomy versus open pyloromyotomy for infantile hypertrophic pyloric stenosis: which is better? J Pediatr Surg 34:370-372
6. Greason KL, Thompson WR, Downey EC, Lo Sasso B (1995) Laparoscopic pyloromyotomy for infantile hypertrophic pyloric stenosis: report of 11 cases. J Pediatr Surg 30:1571-1574

7. Hall NJ, Pacilli M, Eaton S, Reblock K, Gaines BA, Pastor A, Langer JC, Koivusalo AI, Pakarinen MP, Stroedter L, Beyerlein S, Haddad M, Clarke S, Ford H, Pierro A (2009) Recovery after open versus laparoscopic pyloromyotomy for pyloric stenosis: a double-blind multicentre randomised controlled trial. Lancet 373:390-398

8. Leclair MD, Plattner V, Mirallie E, Lejus C, Nguyen JM, Podevin G, Heloury Y (2007) Laparoscopic pyloromyotomy for hypertrophic pyloric stenosis: a prospective, randomized controlled trial. J Pediatr Surg 42:692-698

9. Metzelder ML, Ure BM (2010) Minimally invasive pediatric surgery. Chirurg 81:71-80

10. Rothenberg SS (2007) Thoracoscopic pulmonary surgery. Semin Pediatr Surg 16:231-237

11. Scorpio RJ, Tan HL, Hutson JM (1995) Pyloromyotomy: comparison between laparoscopic and open surgical techniques. J Laparoendosc Surg 5:81-84

12. Sola JE, Neville HL (2009) Laparoscopic vs. open pyloromyotomy: a systematic review and meta-analysis. J Pediatr Surg 44:1631-1637

13. St. Peter SD, Holcomb GW III, Calkins CM, Murphy JP, Andrews WS, Sharp RJ, Snyder CL, Ostlie DJ (2006) Open versus laparoscopic pyloromyotomy for pyloric stenosis: a prospective, randomized trial. Ann Surg 244:363-370

14. Schulz KF, Altman DG, Moher D (2010) CONSORT 2010 statement: updated guidelines for reporting parallel group randomised trials. J Pharmacol Pharmacother 1:100-107

15. Moher D, Schulz KF, Altman DG (2001) CONSORT group (Consolidated standards of reporting trials). The CONSORT statement: revised recommendations for improving the quality of reports of parallel-group randomized trials. J Am Podiatr Med Assoc 91:437-442

16. Campbell BT, McVay MR, Lerer TJ, Lowe NJ, Smith SD, Kokoska ER (2007) Ghosts in the machine: a multi-institutional comparison of laparoscopic and open pyloromyotomy. J Pediatr Surg 42:2026-2029

17. Caceres M, Liu D (2003) Laparoscopic pyloromyotomy: redefining the advantages of a novel technique. JSLS 7:123-127

18. St. Peter SD, Ostlie DJ (2008) Pyloric stenosis: from a retrospective analysis to a prospective clinical trial-the impact on surgical outcomes. Curr Opin Pediatr 20:311-314

19. Hall NJ, van der Zee J, Tan HL, Pierro A (2004) Meta-analysis of laparoscopic versus open pyloromyotomy. Ann Surg 240: 774-778

20. St. Peter SD, Tsao K, Sharp SW, Holcomb GW III, Ostlie DJ (2008) Predictors of emesis and time to goal intake after pyloromyotomy: analysis from a prospective trial. J Pediatr Surg 43:2038-2041

21. Ordorica-Flores R, Leon-Villanueva V, Bracho-Blanchet E, Reyes-Retana R, Dávila-Perez R, Varela-Fascinetto G, TovillaMercado JM, Lezama-DelValle P, Nieto-Zermeño J (2001) Infantile hypertrophic pyloric stenosis: a comparative study of pyloric traumamyoplasty and Fredet-Ramstedt pyloromyotomy. J Pediatr Surg 36:1000-1003

22. Najmaldin A, Tan HL (1995) Early experience with laparoscopic pyloromyotomy for infantile hypertrophic pyloric stenosis. J Pediatr Surg 30:37-38

23. Stassen LP, Bemelman WA, Meijerink J (2010) Risks of minimally invasive surgery underestimated: a report of the Dutch health care inspectorate. Surg Endosc 24:495-498

24. Oomen MW, Hoekstra LT, Bakx R, Heij HA (2010) Learning curves for pediatric laparoscopy: how many operations are 
enough? The Amsterdam experience with laparoscopic pyloromyotomy. Surg Endosc 24:1829-1833

25. Eshuis EJ, Slors JF, Stokkers PC, Sprangers MA, Ubbink DT, Cuesta MA et al (2010) Long-term outcomes following laparoscopically assisted versus open ileocolic resection for Crohn's disease. Br J Surg 97(4):563-568

26. Bertleff MJ, Halm JA, Bemelman WA, van der Ham AC, van der Harst E, Oei HI et al (2009) Randomized clinical trial of laparoscopic versus open repair of the perforated peptic ulcer: the LAMA Trial. World J Surg 33(7):1368-1373

27. Khan IH, McManus KG, McCraith A, McGuigan JA (2000) Muscle sparing thoracotomy: a biomechanical analysis confirms preservation of muscle strength but no improvement in wound discomfort. Eur J Cardiothorac Surg 18(6):656-661 